\title{
Impact of urinary tract and pulmonary infection on mortality after intracerebral hemorrhage in Brazzaville*
}

\author{
P. M. Ossou-Nguiet ${ }^{1, \#}$, B. F. Ellenga-Mbolla ${ }^{2,3}$, A. S. W. Odzebe ${ }^{4}$, G. F. Otiobanda ${ }^{4}$, \\ T. N. Gankama ${ }^{3}$ K. Obondzo-Aloba ${ }^{1}$, T. R. Gombet ${ }^{2}$ \\ ${ }^{1}$ Department of Neurology, University Hospital of Brazzaville, Brazzaville, Congo \\ ${ }^{2}$ Department of Medicine, Health Sciences Faculty of Brazzaville, Brazzaville, Congo \\ ${ }^{3}$ Department of Cardiology, University Hospital of Brazzaville, Brazzaville, Congo \\ ${ }^{4}$ Department of Surgery and Maternity, Faculty of Health Sciences of Brazzaville, Brazzaville, Congo \\ Email: ${ }^{\#}$ doc ossou@yahoo.fr
}

Received 7 August 2013; revised 7 September 2013; accepted 15 September 2013

Copyright (C) 2013 P. M. Ossou-Nguiet et al. This is an open access article distributed under the Creative Commons Attribution License, which permits unrestricted use, distribution, and reproduction in any medium, provided the original work is properly cited.

\begin{abstract}
Objective: To evaluate the impact of urinary tract and pulmonary infection on mortality after cerebral hemorrhage. Method: We conducted at the University Hospital of Brazzaville, a cross-sectional study from January to August 2012 in the emergency department, neurology and intensive care unit. It included patients admitted for cerebral hemorrhage confirmed by CT-scan. A statistical analysis by logistic regression was carried out to evaluate the correlation between infection and death. Result: Among total of 261 patients for stroke, 82 admitted for cerebral hemorrhage ( $31.4 \%)$. The mean age was $55 \pm 11$ years (range 26 to 83 years). The sex ratio men/women was 1.7. Hypertension was the most important risk factor to $80.5 \%$. The average intake in neurology time was $28 \pm 13$ hours. The average time for completion of the CT-scan was $2.4 \pm 2$ days. Thirty-eight (46.3\%) patients had a fever linked to an infectious cause from the third day of hospitalization. The most frequent infectious complications were sepsis $(n=16 \%$; $42 \%)$, pulmonary infection $(n=14 \% ; 37 \%)$ and urinary tract infection $(n=8 \% ; 21 \%)$. Specific mortality of infection was $31.7 \%(n=26)$. The multivariate analysis showed a positive correlation between the occurrence of infection and mortality $(p=0.002)$, specifically between sepsis and mortality $(p=0.0004)$, and an association between the time of admission late in neurology and the occurrence of infectious complications $(p=0.0001)$. Conclusion: Infection is one of the dreaded complications of cerebral hemorrhage. It is often associated with delayed care in specialized areas, and is thereby a preventable cause of death.
\end{abstract}

\footnotetext{
*Conflict of interest: The authors declare no conflict of interest.
}

\#Corresponding author.
Keywords: Infection; Cerebral Hemorrhage; Mortality; Sub-Saharan Africa

\section{INTRODUCTION}

The Intracerebral hemorrhage (ICH) or intra parenchymal hematoma is extravasation of blood into the brain parenchyma. Its incidence is $9-15$ cases per 100.000 inhabitants/year $[1,2]$. There are racial variations, and it is higher among blacks and Asians compared to the rest of the world [3,4]. It represents $10 \%$ to $30 \%$ of stroke [5] in industrialized countries, but $28 \%-60 \%$ in Africa [6]. This is the most severe subtype and the most deadly. Its 30 -day mortality is between $30 \%$ and $50 \%[7,8]$. Survival at 1 year and 5 years was respectively $42 \%$ and $27 \%$. The admission of patients - their early and adapted management in unit stroke helped to reduce the mortality of about $20 \%$ at 1 year [8]. Infectious complications are frequent after stroke; the frequency varies from $5 \%$ to $65 \%$ depending on the series, responsible for high mortality. Pulmonary and urinary locations are most frequently encountered $[9,10]$. The aim of our study was to assess the impact of urinary and pulmonary infection on mortality in the ICH in a Sub-Saharan Africa country.

\section{METHODS}

It was a cross-sectional study conducted from January $1^{\text {st }}$ to August $31^{\text {st }}, 2012$ in the emergency department, neurology and intensive care unit of the University Hospital of Brazzaville. We included all patients admitted for ICH confirmed on CT-scan regardless of age and sex. We did not include patients with subarachnoid or isolate intraventricular hemorrhage, hemorrhagic infarction and posttumor or post-traumatic bleeding. The study variables were: age, sex, cardiovascular risk factors (hypertension, 
diabetes, high cholesterol, alcohol and physical inactivity), delay of admission in neurology, delay for completion of the CT-scan, the location of the bleeding, the temperature, occurrence and localization of infection. The diagnosis of pneumonia was selected by clinical arguments syndrome (fever and pulmonary condensation) and confirmed on chest radiograph. The cytology examination of bronchial secretions was not done because of the difficulties of sampling and interpretation of results. Urinary tract infection was selected to the presence of a germ in a urine test with constant Kass $>105$, in a feverish patient.

Statistical analysis was performed using the software Epiinfo6. The significance level was set at $\mathrm{p} \leq 0.05$. Numeric variables were expressed as mean \pm standard deviation, and categorical variables frequency. The logistic regression analyzes were performed to study the correlation between variables and the occurrence of infection and the impact of infection on the occurrence of mortality. The adjustment of the odds ratio was made for age and sex and initial severity.

\section{RESULTS}

During the study period 261 patients were hospitalized for stroke, $82(31.4 \%)$ of ICH. The mean age was $55 \pm$ 11 years (range 26 to 83 years). Sex male/female ratio was 1.7 . Hypertension was the primary risk factor, found in $80.5 \%$ of cases (Table 1). The average intake in neurology time was $28 \pm 13$ hours, and $61 \%$ of patients were admitted after 24 hours. The average time for completion of the CT-scan was $2.4 \pm 2$ days. Figure 1 shows the distribution according to the location of the bleeding. Thirty-eight $(46.3 \%)$ of patients had an infectious fever in the third day of hospitalization. The most frequent infectious complications were sepsis $42 \%(n=16)$, pulmonary infection $37 \%(\mathrm{n}=14)$ and urinary tract infection $21 \%(n=8)$. Sepsis was from both urinary and pulmonary localization. In all cases, the isolated germ in urine was nosocomial multi-resistant. The mortality of infectious complications was $31.7 \%(n=26)$. Figure 2 shows the distribution of infectious causes of death. In

Table 1. Frequency of risk factors.

\begin{tabular}{ccc}
\hline Risk factors & Number & $\%$ \\
\hline Hypertension & 66 & 80.5 \\
Alcohol & 56 & 68.3 \\
Sedentarity & 49 & 59.8 \\
Hypercholesterolemia & 28 & 34.1 \\
Smoking & 13 & 15.9 \\
Diabetes & 02 & 02.4 \\
\hline
\end{tabular}

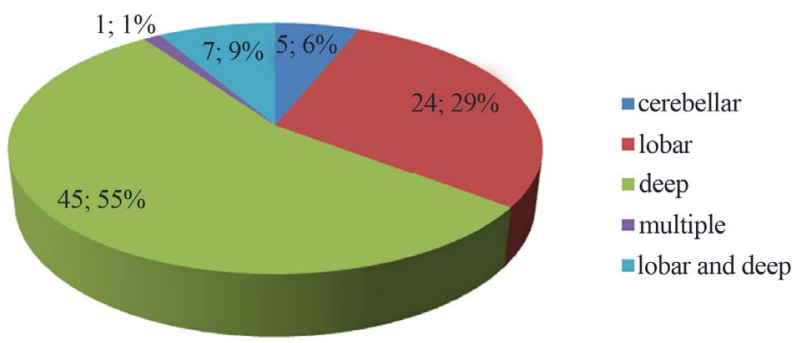

Figure 1. Distribution depending on the location of the bleeding.

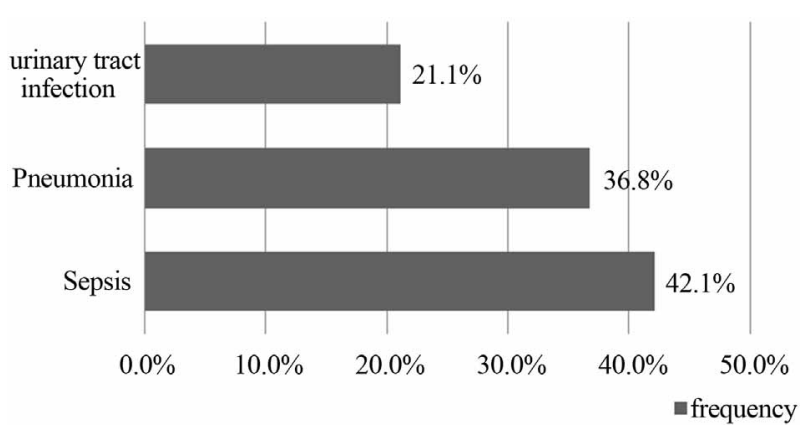

Figure 2. Distribution according to infectious mortality.

multivariate analysis a correlation was found between the late admission in neurology department and the occurrence of infectious complications (OR $=4.3$ [95\% CI 2.9 to 8.7], $\mathrm{p}=0.0001)$. Table 2 shows the analysis of different types of infection according to the vital outcome.

\section{DISCUSSION}

Our study allowed us to determine the frequency of ICH $(31.4 \%)$ of all strokes. This frequency is consistent with data from the literature that estimate the frequency of ICH between $28 \%$ and $60 \%$ in Africa in the series [6]. The dominant role of hypertension among the risk factors is widely accepted, with much higher frequencies in Africa, as in our study $[6,11]$. The predominant of deep location in our study has been reported in many African and Asian studies $[12,13]$. This predominantly reflects the high prevalence of hypertension in these regions, in contrast to a lack of management of hypertensive patients, as reported by Thorogood et al. [14] in South Africa, where over 103 patients who have survived from stroke, $71 \%$ were hypertensive, but only $8 \%$ were taking antihypertensive therapy.

The incidence of infectious complications during the stroke varies from $5 \%$ to $65 \%$ with $1 \%$ to $33 \%$ of pneumonia and $2 \%$ to $27 \%$ of urinary tract infections $[15,16]$, which is similar to our results. Schartz et al. [9] in their series reported an incidence of pneumonia in $43 \%$, and infections of the urinary tract to $35 \%$. Westendorp et al. [10], in their meta-analysis reported that the incidence of infectious complications in stroke varies according to 
Table 2. Analysis of different types of infection according to vital outcome.

\begin{tabular}{cccccc}
\hline & \multicolumn{5}{c}{ Vital outcome } \\
\hline Infectious Complications & Total & Death & Survivors & Ajusted OR [IC 95\%] & $\mathrm{p}$ value \\
Sepsis & 16 & 14 & 2 & $4.32[3.61-9.11]$ & 0.0004 \\
Pneumonia & 14 & 6 & 8 & $1.02[0.58-2.93]$ & 0.512 \\
Urinary tract infection & 8 & 6 & 2 & $2.12[0.97-4.12]$ & 0.051 \\
All infections & 38 & 26 & 12 & $2.68[1.98-3.42]$ & 0.002 \\
\hline
\end{tabular}

whether intensive or non-intensive care unit. In the intensive care unit frequency varies from $38 \%$ to $52 \%$ for all infections, $18 \%$ to $38 \%$ for pneumonia and $0 \%-40 \%$ for urinary tract infections, while outside the intensive care these frequencies are slightly lower with, $22 \%$ $34 \%$ of all infections, $9 \%-10 \%$ for pneumonia and $8 \%$ $11 \%$ for urinary tract infections. The factors favoring the occurrence of infection are: the initial severity, particularly impaired consciousness and the long duration of hospitalization, swallowing disorders and urinary catheterization. In our study, the delay of admission in the neurology department was associated factor $(p=0.0001)$. This can be explained by the fact that swallowing disorders are common in the acute phase of $\mathrm{ICH}$, first causes of pneumonia, while their research and support is not systematic outside neurology departments.

Mortality due to infectious complications is variable depending on the series. Sene Diouf et al. [12] in her study of severe brain hemorrhage noted that sepsis was the leading cause of death for $28 \%$ of cases. Westendorp et al. [10] reported the risk due to infection during a stroke, with an OR $=2.08$ (95\% CI: $1.63-2.67)$, which approximates our results, and the lack of correlation between urinary infection and mortality. However, the same study reported a strong association between pneumonia and death $(\mathrm{OR}=5.58 \%, 95 \%$ CI: 4.76 to 6.55$)$, whereas we did not find any association. Mortality from sepsis is mainly due to two factors through the temperature rise which has been identified in several studies as a factor of poor outcome $[17,18]$, or by direct action of infection with pulmonary and urinary location were the most frequently found and associated with a poor outcome [19, 20], and the germ is the most frequently isolated nosocomial as also reported Westendorp et al. [10].

\section{CONCLUSION}

Infectious complications, particularly pneumonia and urinary tract infections are common during cerebral hemorrhage, and most often associated with a poor outcome because the germ is most commonly isolated nosocomial. Their prevention is a good hospital and personal hygiene, early detection of swallowing disorders, and supported by the placement of a nasogastric tube, and strict aseptic conditions in a pose of the urinary catheterization.

\section{REFERENCES}

[1] Benatru, I., Rouaud, O., Durier, J., Contegal, F., Couvreur, G., Bejot, Y., et al. (2006) Stable stroke incidence rates but improved case fatality in Dijon, France, from 1985 to 2004. Stroke, 37, 1674-1679.

http://dx.doi.org/10.1161/01.STR.0000226979.56456.a8

[2] Gebel, J.M. and Broderick, J.P. (2000) Intracerebral hemorrhage. Neurologic Clinics, 18, 419-438. http://dx.doi.org/10.1016/S0733-8619(05)70200-0

[3] Copenhaver, B.R., Hsia, A.W., Merino, J.G., Burgess, R.E., Fifi, J.T., Davis, L., et al. (2008) Racial differencies in microbleeds prevalency in intracerebral haemorrhage primaire. Neurology, 71, 1176-1182. http://dx.doi.org/10.1212/01.wnl.0000327524.16575.ca

[4] Rincon, F., Lyden, P. and Mayer, S.A. (2012) The Epidemiology of intracerebral Hemorrhage in the United States from 1979 to 2008. Springer Science, 77, 524-532.

[5] Gage, B.F., Yan, Y., Milligan, P.E., Waterman, A.D., Culverhouse, R., Rich, M.W., et al. (2006) Clinical classification schemes for predicting hemorrhage: Results from the National Registry of Atrial Fibrillation (NRAF). American Heart Journal, 151, 713-719. http://dx.doi.org/10.1016/j.ahj.2005.04.017

[6] Adoukonou, T.A., Vallat, J.M., Joubert, J., Macian, F., Kabore, R., Magy, L., et al. (2010) Prise en charge des accidents vasculaires cérébraux en Afrique subsaharienne. Revue Neurologique, 166, 882-893.

http://dx.doi.org/10.1016/j.neurol.2010.06.004

[7] Fogelholm, R., Murros, K., Rissanen, A. and Avikainen, S. (2005) Long term survival after primary intracerebral haemorrhage: A retrospective population based study. Journal of Neurology, Neurosurgery \& Psychiatry, 76, 1534-1538. http://dx.doi.org/10.1136/jnnp.2004.055145

[8] Grillo, P., Velly, L. and Bruder, N. (2006) Accidents vasculaires cérébraux hémorragiques: Nouveautés de prise en charge. Annales Françaises d'Anesthésie et de Réanimation, 25, 868-873. http://dx.doi.org/10.1016/j.annfar.2006.03.030

[9] Schwarz, S., Häfner, K., Aschoff, A. and Schwab, S. (2000) Incidence and prognostic significance of fever following intracerebral hemorrhage. Neurology, 54, 354 361. http://dx.doi.org/10.1212/WNL.54.2.354 
[10] Westendorp, W.F., Nederkoorn, P.J., Vermeij, J.D., Dijkgraaf, M.G. and Van de Beek, D. (2011) Post-stroke infection: A systematic review and meta-analysis. BMC Neurology, 11, 110.

http://dx.doi.org/10.1186/1471-2377-11-110

[11] Sagui, E. (2007) Les accidents vasculaires cérébraux en Afrique subsaharienne. Médecine Tropicale, 6, 596-600.

[12] Sène Diouf, F., Mapoure, N.Y., Ndiaye, M., Mbatchou Ngahane, H.B., Touré, K., Thiam, A., et al. (2008) Pronostic des hémorragies intracérébrales avec coma dans une unité de neuroréanimation tropicale. Médecine Tropicale, 68, 606-610.

[13] Kim, K.-H. (2009) Predictors of 30-day mortality and 90-day functional recovery after primary intracerebral hemorrhage: Hospital based multivariate analysis in 585 patients. Journal of Korean Neurosurgical Society, 45, 341-349. http://dx.doi.org/10.3340/jkns.2009.45.6.341

[14] Thorogood, M., Connor, M.D., Kewando-Hundt, G., Tollman, S. and Ngoma, B. (2004) SASPI project team. Secondary prevention of stroke-results from the Southern Africa stroke prevention initiative (SASPI) study. Bulletin of the World Health Organization, 82, 503-508.

[15] Emsley, H.C. and Hopkins, S.J. (2008) Acute ischemic stroke and infection: Recent and emerging concepts. The Lancet Neurology, 7, 341-353. http://dx.doi.org/10.1016/S1474-4422(08)70061-9

[16] Vermeij, F.H., Scholte, O.P., Reimer, W.J., de Man, M.P.,
Van Oostenbrugge, R.J., Franke, C.L., et al. (2009) Strokeassociated infection is an independent risk factor for poor outcome after acute ischemic stroke: Data from the Netherlands stroke survey. Cerebrovascular Diseases, 27, 465-471. http://dx.doi.org/10.1159/000210093

[17] De Herdt, V., Dumont, F., Henon, H., Derambre, P., Vonck, K., Leys, D., et al. (2011) Early seizures in intracerebral hemorrhage. Neurology, 77, 1794-1800. http://dx.doi.org/10.1212/WNL.0b013e31823648a6

[18] Balami, J.S. and Buchan, A.M. (2012) Complications of intracerebral haemorrhage. The Lancet Neurology, 11, 101-118. http://dx.doi.org/10.1016/S1474-4422(11)70264-2

[19] Commichau, C., Scarmeas, N. and Mayer, S.A. (2003) Risk factors for fever in the neurologic intensive care unit. Neurology, 60, 837-841. http://dx.doi.org/10.1212/01.WNL.0000047344.28843.E B

[20] Mayer, S.A., Kowalski, R.G., Presciutti, M., Ostapkovich, N.D., McGann, E., Fitzsimmons, B.F., et al. (2004) Clinical trial of a novel surface cooling systemfor fever control in neurocritical care patients. Critical Care Medicine, 32, 2508-2515. http://dx.doi.org/10.1097/01.CCM.0000147441.39670.37

\section{AUTHORSHIP}

Ossou-Nguiet PM, Ellenga-Mbolla and Odzebe participate to: conception and design of the study, analysis and interpretation of data, drafting of article.

Otiobanda GF participate to: analysis and interpretation of data, revision of submitted article.

Gankama TN participate to: acquisition, analysis and interpretation of data, drafting.

Gombet TR: design of study and revision of submit article. 